\title{
Both Neuropeptide $Y$ and Serotonin Are Necessary for Entrainment of Circadian Rhythms in Mice by Daily Treadmill Running Schedules
}

\author{
Elliott G. Marchant, Neil V. Watson, and Ralph E. Mistlberger \\ Department of Psychology, Simon Fraser University, Burnaby, British Columbia V5A 1S6, Canada
}

\begin{abstract}
This study investigated the role of the suprachiasmatic nucleus (SCN) circadian pacemaker and its neuropeptide Y (NPY) and serotonin (5-HT) afferents in entrainment (synchronization) of mouse circadian rhythms by treadmill running. Blind C57BL/6j mice were run in treadmills for $3 \mathrm{hr} / \mathrm{d}$ for 3-10 weeks after receiving radio-frequency lesions of the SCN or the intergeniculate leaflet (IGL, the source of SCN NPY) or infusions of the 5-HT neurotoxin 5,7-DHT into the SCN area. Of 25 intact mice, 22 entrained and three showed period $(\tau$, the mean duration of the circadian cycle) modulations to scheduled running. Arrhythmic SCN-ablated mice did not synchronize to scheduled running in a way suggestive of circadian pacemaker mediation. Of 15 mice with IGL lesions, only two with partial lesions entrained. Mice with complete IGL lesions (five), confirmed by immunocytochemistry, showed no entrainment or $\tau$ changes. Of 19
\end{abstract}

mice with 5-HT lesions, only two with partial lesions entrained. All but two mice with complete (10) or nearly complete (4) 5-HT denervation, confirmed by immunocytochemistry, showed $\tau$ modulations during the treadmill schedule. Failure to entrain was not explained by group differences in $\tau$ before the treadmill schedules. The results indicate that the SCN and both NPY and 5-HT are necessary for entrainment to $24 \mathrm{hr}$ schedules of forced running but that complete loss of 5-HT does not prevent modulations of pacemaker motion by behavioral stimuli. Treadmill entrainment in mice may involve synergistic interactions between 5-HT and NPY afferents at some site within the circadian system.

Key words: circadian rhythms; entrainment; neuropeptide Y; serotonin; intergeniculate leaflet; raphe nuclei; suprachiasmatic nucleus; treadmill running
Circadian rhythms in mammals entrain to daily light/dark (LD) cycles and persist (i.e., free-run) in environments devoid of such time cues (zeitgebers). The pacemaker critical for the generation of photically entrainable circadian rhythms is located in the suprachiasmatic nucleus (SCN) of the anterior hypothalamus (Klein et al., 1991). Photic entrainment of this pacemaker is mediated by a direct retinohypothalamic pathway, probably releasing glutamate (Ebling, 1996; Miller et al., 1996). Circadian rhythms can also be shifted or entrained by a variety of nonphotic stimuli (Turek and Losee-Olsen, 1986; Mrosovsky, 1988; Van Reeth and Turek, 1989; Edgar and Dement, 1992; Hastings et al., 1995; Marchant and Mistlberger, 1995; Ebihara et al., 1996; Marchant and Mistlberger, 1996; Mistlberger et al., 1996, 1997). These stimuli seem in most cases to affect the pacemaker by inducing behavioral activity, because if activity is prevented, phase shifts or entrainment are usually absent (e.g., Van Reeth and Turek, 1989; Mrosovsky and Salmon, 1990; Mistlberger et al., 1996, 1997). In at least one case, phase shifts are related to a stress

\footnotetext{
Received May 8, 1997; revised July 25, 1997; accepted July 29, 1997.

This work was supported by grants from National Science and Engineering Research Council, Canada, to R.E.M. We are grateful to Jennifer Bossert and Melissa Holmes for technical assistance, to Beth Meyer-Bernstein and Drs. Mary Harrington and Joe Miller for comments on portions of this manuscript, to Dr. Larry Morin for the use of the densitometry imaging system, and to the Department of Kinesiology at Simon Fraser University for the use of rodent treadmills.

Before Jan. 1, 1998, correspondence should be addressed to Dr. Ralph Mistlberger, 2018 Carquinez Avenue, El Cerrito, CA 94530; after Jan 1, 1998 and for reprints, correspondence should be addressed to Dr. Ralph Mistlberger, Department of Psychology, Simon Fraser University, Burnaby, BC V5A 1S6, Canada.

Dr. Elliott Marchant's present address: Department of Psychiatry and Behavioral Sciences, State University of New York, Stony Brook, NY 11794.

Copyright (C) 1997 Society for Neuroscience $0270-6474 / 97 / 177974-14 \$ 05.00 / 0$
}

response induced by the nonphotic stimulus (Hastings et al., 1995).

Two afferent pathways to the SCN that may contribute to phase shifting and entrainment by arousing, nonphotic stimuli include the geniculohypothalamic tract, which is a set of fibers containing NPY, GABA, and possibly other transmitters emanating from the thalamic intergeniculate leaflet (IGL) (Harrington et al., 1985; Morin et al., 1992), and a serotonergic input from the midbrain raphe nuclei (Azmitia and Segal, 1978; Meyer-Bernstein and Morin, 1996). Elimination of NPY input to the SCN by IGL ablation in hamsters and mice is reported to attenuate nonphotic shifting or prevent entrainment in response to running induced by triazolam, novel wheels, or home cage wheels (Johnson et al., 1988; Janik and Mrosovsky, 1994; Wickland and Turek, 1994; Edgar et al., 1997). However, because IGL lesions also attenuate the amount of activity induced by these stimuli, failure to shift or entrain may be caused by an inadequate nonphotic stimulus, rather than by loss of a necessary nonphotic input pathway to the pacemaker. This confound is particularly problematic for interpreting the role of NPY in mice, given that studies using other methods have not yet been done in this species. Similarly, reduced activity cannot be ruled out as the explanation for attenuation of nonphotic shifting in hamsters after neurochemical depletion of serotonin (5-HT) (Cutrera et al., 1994; Penev et al., 1995).

We reported previously that mice are avid treadmill runners, and that $3 \mathrm{hr}$ of forced treadmill running each day can entrain free-running rhythms in blind mice with the same apparent efficacy (percentage of mice entraining and time required to entrain) and characteristics (phase angle of entrainment) as $3 \mathrm{hr}$ of voluntary running in a home cage wheel (Marchant and Mistlberger, 1996). That study resolved the issue of whether voluntary and 
forced running differ in value as nonphotic zeitgebers and established a method for evaluating nonphotic entrainment in animals sustaining lesions that reduce voluntary or drug-stimulated activity. In the present study, after determining that the SCN is the site of the pacemaker necessary for entrainment to daily treadmill schedules, we demonstrate that lesions eliminating either NPY or 5-HT from the SCN in mice do not impair treadmill running but do prevent entrainment to daily schedules of forced running.

\section{MATERIALS AND METHODS}

Sixty-eight male C57BL/6j mice (2-4 months of age; Charles River Laboratories, Montreal, Quebec, Canada) were housed individually in plastic cages $(47 \times 26 \times 20 \mathrm{~cm})$ with contact drinkometers monitored continuously by microcomputer using the Activity Counting System interface and software (Simon Fraser University). All mice were maintained for at least 1 week in $12 \mathrm{hr}$ LD cycles before being blinded by enucleation during the last $3 \mathrm{hr}$ of the light period. During the treadmill schedules, the animals were removed from their home cages every $24 \mathrm{hr}$, transferred to a treadmill lane $(45 \times 12 \times 9 \mathrm{~cm})$, and run for three $50 \mathrm{~min}$ sessions $(16 \mathrm{~m} / \mathrm{min}$ or $2.8 \mathrm{~km} / \mathrm{session})$, separated by $10 \mathrm{~min}$ breaks for food and water. Compressed air, triggered by a photocell at the end of each lane, was used to minimize passive riding of the treadmill. The mice were tested in five groups as follows:

Group 1 mice $(n=16)$ were run in the treadmill $3 \mathrm{hr} / \mathrm{d}$ for $42 \mathrm{~d}$, beginning $7-10 \mathrm{~d}$ after enucleation.

Group 2 mice $(n=9)$ were run on the treadmill schedule for $25-60 \mathrm{~d}$, beginning the day after enucleation.

Group 3 mice $(n=9)$ received bilateral SCN ablations and enucleation and were recorded undisturbed for at least $21 \mathrm{~d}$ before being run on the treadmill $3 \mathrm{hr} / \mathrm{d}$ for $22 \mathrm{~d}$. All of these mice were used previously in a food restriction study and were selected on the basis of displaying disrupted activity patterns in constant conditions.

Group 4 mice $(n=15)$ received bilateral IGL ablations, $11-17 \mathrm{~d}$ of recovery in the LD cycle, and then $42-51 \mathrm{~d}$ of scheduled treadmill running beginning 7-10 $\mathrm{d}$ after enucleation. Nine of the mice had access to home cage running wheels.

Group 5 mice $(n=19)$ received infusions of the 5-HT-specific neurotoxin 5,7-DHT into the SCN area, 7-10 d of recovery in the LD cycle, and then 32-74 $\mathrm{d}$ of scheduled treadmill running beginning 7-10 d after enucleation.

All groups were left undisturbed, apart from routine maintenance, for at least $10 \mathrm{~d}$ after the treadmill schedules. Animals were then killed, and their brains were subjected to standard histological procedures. Killing of 5,7-DHT-treated and IGL-ablated mice were timed to occur at or around activity onset.

Surgery. All surgery was conducted stereotaxically (Kopf mouse adapter) with a xylazine $(2-3 \mathrm{mg} / \mathrm{kg})$ and ketamine $(0.4 \mathrm{mg} / \mathrm{kg})$ cocktail as the general anesthetic. Radio-frequency lesions were made by passing current $(20-25 \mathrm{~mA} ; 15 \mathrm{sec})$ through a " 00 " insulated insect pin with a 0.3 $\mathrm{mm}$ blunt tip. Stereotaxic coordinates for the SCN ablations were 0.6 and $0.1 \mathrm{~mm}$ anterior to bregma and 5.8 and $5.7 \mathrm{~mm}$ ventral to the dura at the midline. The IGL coordinates were 1.6 and $2.0 \mathrm{~mm}$ posterior to bregma, 3.0 and $3.4 \mathrm{~mm}$ ventral from the skull, and $\pm 2.1 \mathrm{~mm}$ lateral from the midline.

Mice sustaining 5,7-DHT lesions first received an intraperitoneal injection of desipramine ( $30 \mathrm{mg} / \mathrm{kg}$; Sigma, St. Louis, MO) $30 \mathrm{~min}$ before surgery to protect catecholamine terminals. Each animal received two injections of 5,7-DHT ( $40 \mu \mathrm{g}$ of free base in $2.5 \mu \mathrm{l}$ of $0.9 \%$ saline and $0.2 \%$ ascorbic acid) aimed at the SCN. Injections were made over a $3 \mathrm{~min}$ period via a stereotaxically placed 33 gauge injection cannula. The cannula was left in place for an additional $3 \mathrm{~min}$ period to reduce backflow. Stereotaxic coordinates were $0.1 \mathrm{~mm}$ anterior and $0.3 \mathrm{~mm}$ posterior to bregma and $5.5 \mathrm{~mm}$ ventral to the dura at the midline.

Histological procedures. All mice were perfused transcardially with ice-cold $0.1 \mathrm{M}$ PBS $(100 \mathrm{ml})$, followed by $4 \%$ paraformaldehyde $(100 \mathrm{ml})$. The brains were removed and post-fixed for $4.5 \mathrm{hr}$ [NPY immunoreactivity (IR)] or $2 \mathrm{hr}$ (5-HT-IR) in $4 \%$ paraformaldehyde before being stored in a $20 \%$ sucrose solution overnight. SCN ablations were sectioned on a cryostat $(50 \mu \mathrm{m})$ and stained using cresyl violet.

In the IGL-ablated animals, two series of brain sections were cut (50 $\mu \mathrm{m}$ ) into PBS from the anterior commissure to the retrochiasmatic areas using a freezing stage microtome. The first series was developed for NPY-IR, whereas the second series was transferred to deOlmos cryo- protectant (adapted from Watson et al., 1986) for subsequent 5-HT immunocytochemistry. Sections caudal to the retrochiasmatic area were cut on a cryostat $(50 \mu \mathrm{m})$ and stained with cresyl violet to assess lesion placement.

The brains of 5,7-DHT-treated animals were processed in the same manner as the IGL-ablated brains with the exceptions of an additional perfusate [picric acid $(5 \%)$ and gluteraldehyde $(3 \%)$ in paraformaldehyde (4\%) in PBS] and one complete series of sections being developed for 5-HT-IR, with the second series stored in cryoprotectant for subsequent NPY immunocytochemistry.

Immunocytochemistry. Brain sections were washed in PBS-gelatin and Triton X-100, followed by a 90 min incubation in $10 \%$ normal goat serum (Vector Laboratories, Burlingame, CA) and a $36 \mathrm{hr}$ incubation in polyclonal rabbit anti-NPY $(1: 15,000$; Peninsula Laboratories) or polyclonal rabbit anti-5-HT $\left(1: 35,000\right.$; Incstar, Inc.) at $4^{\circ} \mathrm{C}$. The tissue was then rinsed in PBS-gelatin and Triton X-100, and endogenous biotin was blocked through incubation with excess avidin followed by excess biotin. After additional washes, the tissue was incubated for $1 \mathrm{hr}$ at $20^{\circ} \mathrm{C}$ in anti-rabbit secondary. After rinsing, the tissue was incubated in avidinbiotin-peroxidase complex (Vector ABC Elite; $1 \mathrm{hr} ; 20^{\circ} \mathrm{C}$ ) and visualized using $\mathrm{H}_{2} \mathrm{O}_{2}$ and $0.05 \mathrm{M}$ diaminobenzidine in Tris buffer, $\mathrm{pH}$ 7.2, intensified with $1 \% \mathrm{NiCl}$. The tissue was washed, mounted on slides, dried, cleared, and coverslipped.

Anatomical analyses. The density of NPY-IR and 5-HT-IR was initially evaluated by visual inspection of all SCN sections. The SCN in each section was scored on a three-point scale by two independent raters; a score of 1 signified no IR in the SCN, 2 indicated light IR, and 3 indicated dense IR. A mean score was calculated based on all sections examined. Complete lesions were defined as those in which NPY-IR or 5-HT-IR was absent from all regions of the SCN. A microcomputer imaging device (Imaging Research, Brock University) was used for semiquantitative densitometry. A relative optical density (ROD) score was produced for the single SCN section from each animal that exhibited the darkest IR for NPY or 5-HT. For mice with IGL ablations, ROD scores were normalized by dividing by the ROD score obtained from the hypothalamic paraventricular nucleus (PVN). For mice with 5,7-DHT ablations, RODs were also obtained for 5-HT-IR in the IGL and the anterior commissure, the latter of which was used for normalization.

Behavior analyses. Drinking contacts and wheel revolutions were counted and stored to disk at 10 min intervals and periodically downloaded to a Macintosh computer for display and analysis. Data were visualized in the form of standard double-plotted "actograms" and average waveforms. The period $(\tau)$ of free-running rhythms was measured by regression lines fit to computer-detected onsets of the daily active period $(\alpha)$. Rhythms were scored as entrained if they assumed a stable phase relationship to the daily treadmill schedule for at least the last $7 \mathrm{~d}$ and if they free-ran from that phase when the schedule was terminated. The latency to entrainment was defined as the number of days from the start of the treadmill schedule to the day that activity onset occurred within $30 \mathrm{~min}$ of a line fit to activity onsets in the entrained state. The phase angle of entrainment was defined as the number of hours that activity onset preceded the daily treadmill session in the entrained state. Group differences in rhythm parameters were assessed by ANOVA and Tukey honestly significant difference tests or paired $t$ tests. All means are reported $\pm \mathrm{SE}$.

\section{RESULTS}

\section{Histology}

\section{Intact mice}

The organization of NPY and 5-HT afferents within the SCN of two intact mice was generally similar to that described previously for the Syrian hamster (Morin et al., 1992). NPY-IR fibers were evenly distributed throughout the circular core at the rostral and middle SCN levels (Fig. 1 $A, B$ ). ROD scores averaged 0.37 (range, 0.36-0.38), and ratios with respect to the PVN averaged 0.74. No fibers were evident in a shell surrounding this core laterally, dorsally, and medially. Dense IR was evident within the periventricular region surrounding the third ventricle and the tractus infundibularis between the SCN. Some IR was also evident in the optic chiasm along the ventral border of the SCN. More caudally, NPY-IR remained dense in the most ventral 

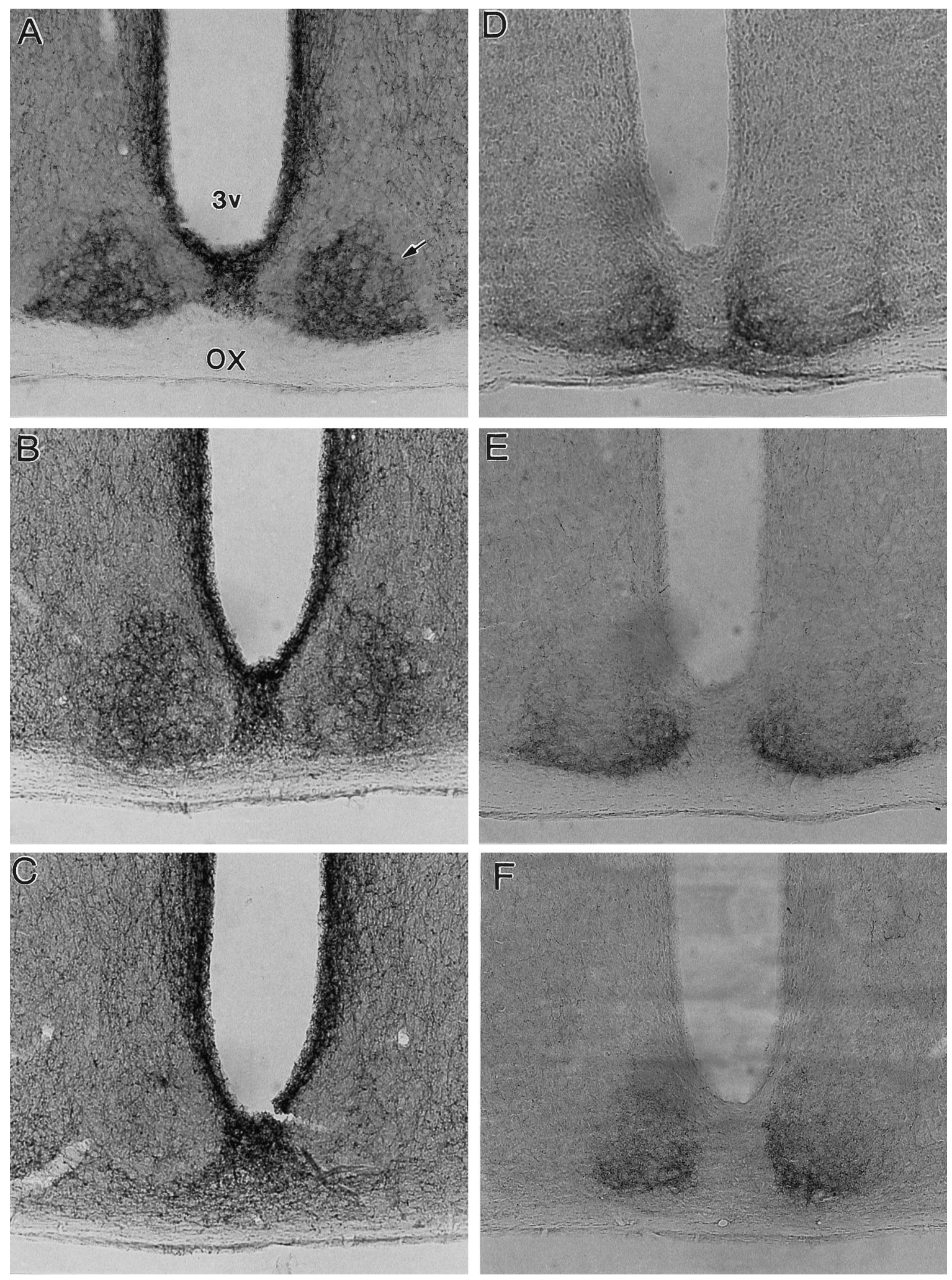

Figure 1. Photomicrographs of NPY-IR $(A-C)$ and 5-HT-IR $(D-F)$ in the SCN of two untreated mice. Rostral, middle, and caudal levels of the SCN are shown. The most rostral pole of the SCN is not shown. Arrow denotes SCN. OX, Optic chiasm.

SCN, but fibers were sparsely distributed in the core region. NPY-IR was absent from the most rostral and caudal (Fig. 1C) poles of the SCN. This organization is consistent with that described for the ZRDCT mouse (Laemle et al., 1993).
In contrast to NPY-IR, 5-HT-IR in the SCN exhibited a cup-like configuration, with heavy labeling ventrally and medially (where NPY was primarily absent) but little labeling dorsolaterally (Fig. $1 D, E)$. This configuration was less evident very ros- 

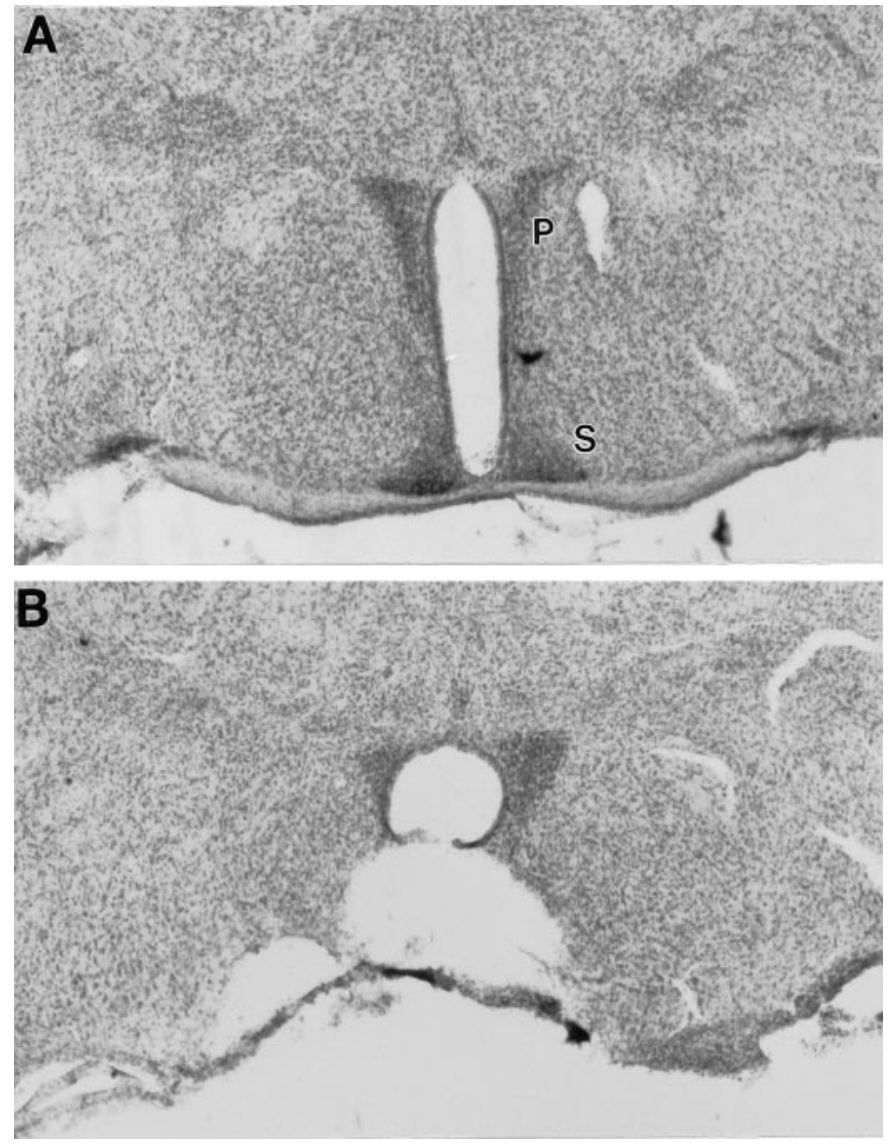

Figure 2. Photomicrographs of the SCN area in a mouse sustaining a complete SCN ablation $(B)$ and in a sham-lesioned mouse $(A)$. $P$, Paraventricular nucleus; $S$, suprachiasmatic nucleus.

trally, where IR was evident primarily just dorsal to the optic chiasm, or caudally, where more IR fibers were evident throughout the core of the SCN (Fig. $1 F$ ), similar to NPY-IR. ROD scores averaged 0.69 (range, 0.52-0.75), and ratios with respect to the anterior commissure averaged 4.18 (range, 3.96-4.41).

\section{SCN lesions}

Of the nine mice subjected to the treadmill schedule, eight sustained unambiguously complete SCN lesions (e.g., Fig. 2B), and one sustained a nearly complete ablation in which survival of a few SCN fragments could not be ruled out. The lesions were large in all cases and typically partially damaged adjacent structures, including the preoptic and anterior hypothalamic and retrochiasmatic areas, the PVN, and the periventricular, arcuate, and ventromedial nuclei.

\section{IGL lesions}

Three out of the 15 mice were not assessed for NPY-IR because of early death. Five mice were judged by both raters to have no NPY-IR in the SCN (Fig. 3A). SCN RODs averaged $0.28 \pm 0.05$, and ratios with respect to the PVN averaged $0.54 \pm 0.04$. Inspection of Nissl-stained sections confirmed that in all five cases, there were large lesion cavities in the location of the IGL (e.g., Fig. 4). Complete lesions typically also damaged the hippocampus (CA2 and CA3 regions), fimbria, reticular thalamic nucleus, ventral posterolateral thalamic nucleus, ventral posteromedial lateral thalamic nucleus, superior thalamic radiation, dorsal lateral genicu-
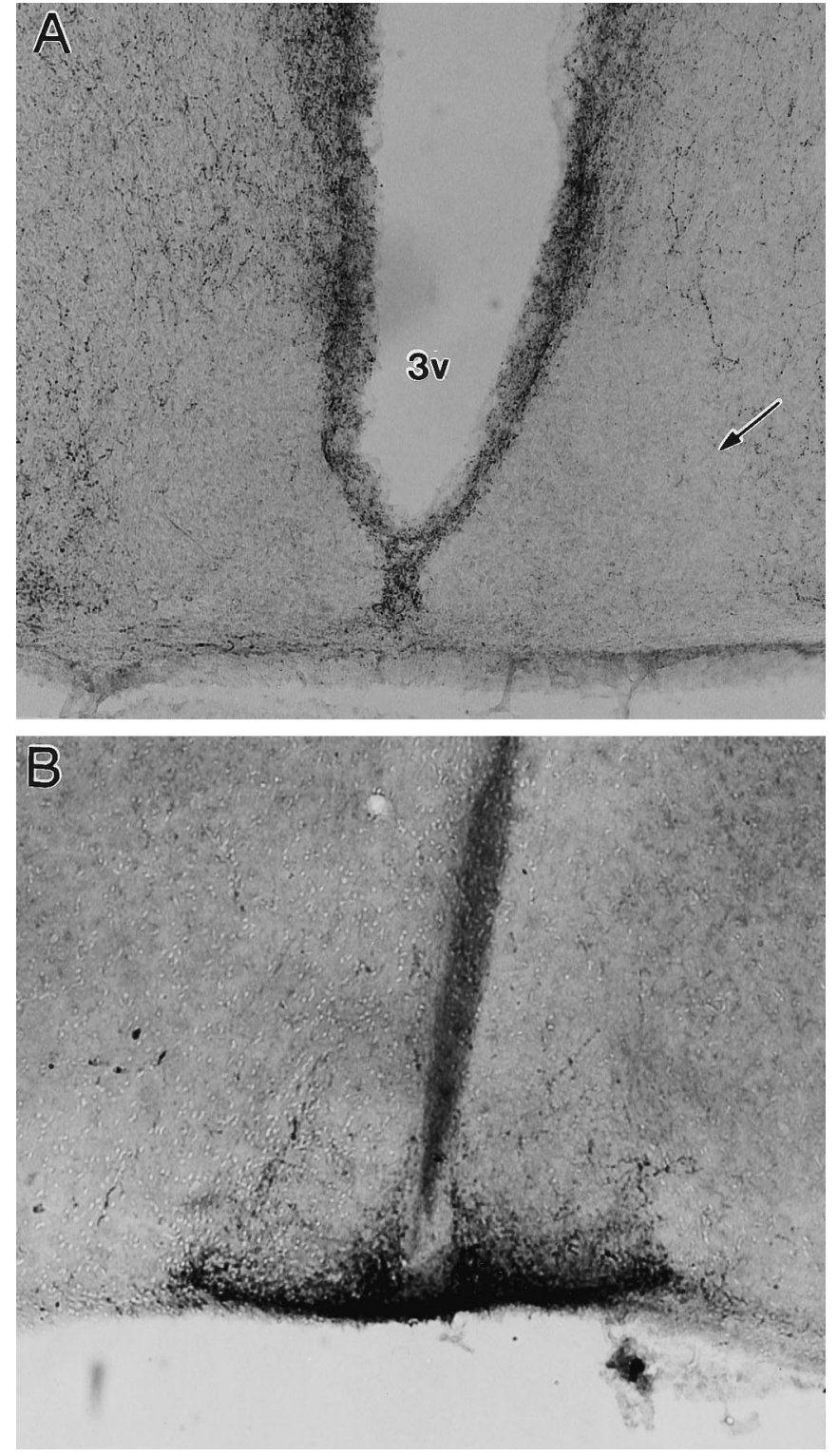

Figure 3. Photomicrographs of the $\mathrm{SCN}$ in a mouse sustaining complete IGL ablation. $A$, NPY-IR is absent. $B, 5$-HT-IR is normal in density and distribution. Arrow denotes SCN.

late, and ventral lateral geniculate nucleus. NPY-IR in other structures (i.e., the PVN) seemed to be unaffected by the IGL lesions.

Seven mice were rated as having partial IGL lesions. NPY-IR was detectable in one or more sections of the SCN in these mice, and the group mean ROD score for the densest SCN section was significantly higher than that for the mice with complete lesions (mean, $0.33 \pm 0.04 ; t=3.29 ; p=0.01$ ). Ratios with respect to the PVN were also higher (mean, $0.73 \pm 0.13$ ). However, overall density was in most cases substantially lower than in unlesioned mice because many SCN sections displayed little or no IR. In animals with partial IGL lesions, damage tended to be focused lateral, dorsal, and caudal to the IGL.

Sections containing the SCN from the five mice with complete lesions were also examined for 5-HT-IR to determine whether IGL lesions might affect 5-HT innervation of the SCN. All of 

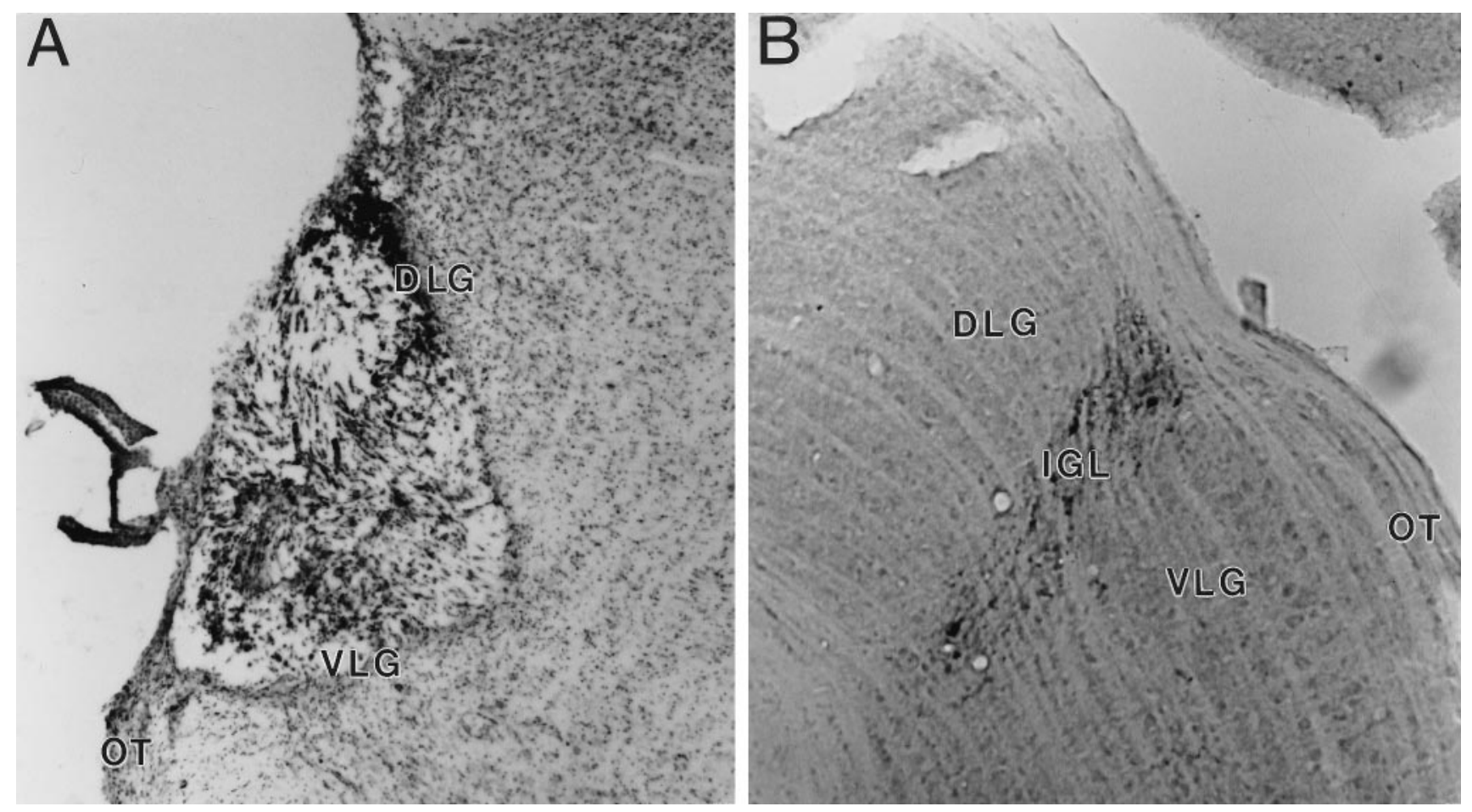

Figure 4. Photomicrographs of the IGL area from a mouse sustaining a lesion that eliminated NPY from the SCN ( $A$; Nissl stain) and from an intact mouse ( $B$; IGL cells labeled with NPY). $D L G$, Dorsal lateral geniculate; $V L G$, ventral lateral geniculate; and $O T$, optic tract.

these mice showed strong 5-HT-IR in the SCN (Fig. 3B), similar in density and organization to that of the unlesioned mice.

\section{5-HT lesions}

Seventeen of 19 mice that received 5,7-DHT infusions were treated for 5-HT-IR. Of these, 10 showed no detectable 5-HT-IR in any section of the SCN (Fig. $5 A$ ), four showed only a few fibers evident in most sections (Fig. 6), and three showed IR similar in organization and apparent intensity to that of intact mice (Fig. $5 B, C)$. Mean RODs were similar in mice with no apparent 5-HT-IR and in mice with a few IR fibers $(0.13 \pm 0.01$ and $0.18 \pm$ 0.01 , respectively) and were substantially higher in mice with dense IR (mean, $0.34 \pm 0.01$ ). The 14 mice with little or no 5-HT-IR in the SCN also showed very low levels of IR throughout most of the hypothalamus (Fig. 5A). However, IR fibers were evident in the IGL in all animals, and there was no clear evidence by visual inspection that 5,7-DHT-treated and intact mice differed. Nonetheless, RODs for the IGL averaged $0.50(0.47-0.54)$ in the two intact mice, $0.29 \pm 0.02$ in the lesioned mice with substantial SCN 5-HT-IR, and $0.37 \pm 0.03$ in mice with little or no SCN 5-HT-IR, suggesting some loss of fibers. Dense IR was evident in the dorsal and median raphe nuclei in all animals.

Cryoprotected sections from the 5,7-DHT-treated group were also processed for NPY-IR in the SCN. NPY-IR was weak and variable in the SCN and other hypothalamic areas (e.g., the PVN) in these sections, regardless of the degree of 5-HT denervation. NPY-IR was clearly evident in some mice with complete 5-HT depletion, but this was less certain in other cases. Weak IR was probably caused by the use of glutaraldehyde in the perfusate, because this has been reported previously to reduce NPY-IR in rat brain (Guy et al., 1987). Consistent with other studies (Guy et al., 1987), there was no clear evidence from this analysis that 5,7-DHT attenuated NPY levels specifically in the SCN.

\section{Behavior: treadmill running and entrainment} General observations

All mice in the intact and lesion groups ran in the treadmill at the target rate of $16 \mathrm{~m} / \mathrm{min}$. During the treadmill sessions, mice tended to run to the top of the treadmill lane and ride the lane back to a point just before compressed air was triggered. This pattern of starts and stops mimics natural activity patterns in mice. Mice ate and drank little during the treadmill sessions, although nibbling of food pellets and sipping of water were occasionally observed during the 10 min hourly breaks, which were otherwise occupied by grooming. There were no obvious differences in behavior between intact and lesioned animals.

\section{Entrainment: intact mice}

Behavioral results are summarized in Table 1. In the intact mice of group 1, treadmill running was initiated during early-to-late $\alpha$ and resulted in stable entrainment in 14 of 16 animals, with a latency of $19 \pm 3 \mathrm{~d}$. During this time, $\tau$ seemed to lengthen gradually toward $24 \mathrm{hr}(\mathrm{Fig}$. $7 A-C)$. The phase angle of entrainment was positive, with the onset of drinking activity preceding the daily treadmill sessions by $11 \pm 1 \mathrm{hr}$. After the treadmill schedule, the drinking activity rhythm free-ran from the apparent phase angle of entrainment in animals that were scored as entrained.

Intact mice of group 2 were subjected to scheduled treadmill running beginning the day after enucleation. This was designed to assess whether the latency to stable entrainment could be reduced by preventing the expression of a short $\tau$ free-run. Treadmill running was initiated during middle-to-late $\alpha$ and resulted in stable entrainment for at least the last $7 \mathrm{~d}$ in eight of nine animals, after $23 \pm 1 \mathrm{~d}$ of delaying transients (Fig. $7 D$ ). The phase angle of entrainment was positive, with drinking activity onset preced- 

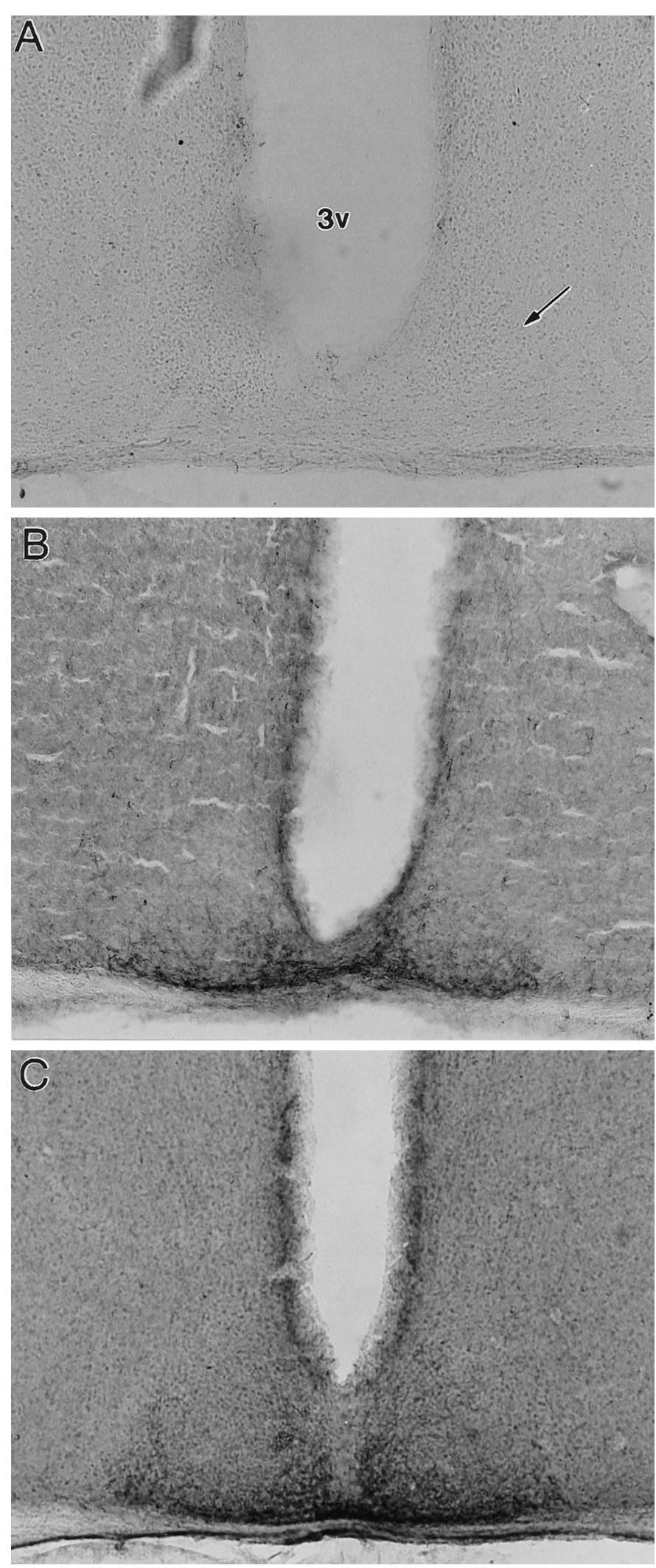

Figure 5. Photomicrographs of 5-HT-IR in a 5,7-DHT-treated mouse exhibiting complete 5-HT denervation $(A)$ and in two 5,7-DHT-treated mice with substantial sparing or regrowth of 5-HT fibers $(B, C)$. Arrow points to middle SCN. $3 V$, Third ventricle.
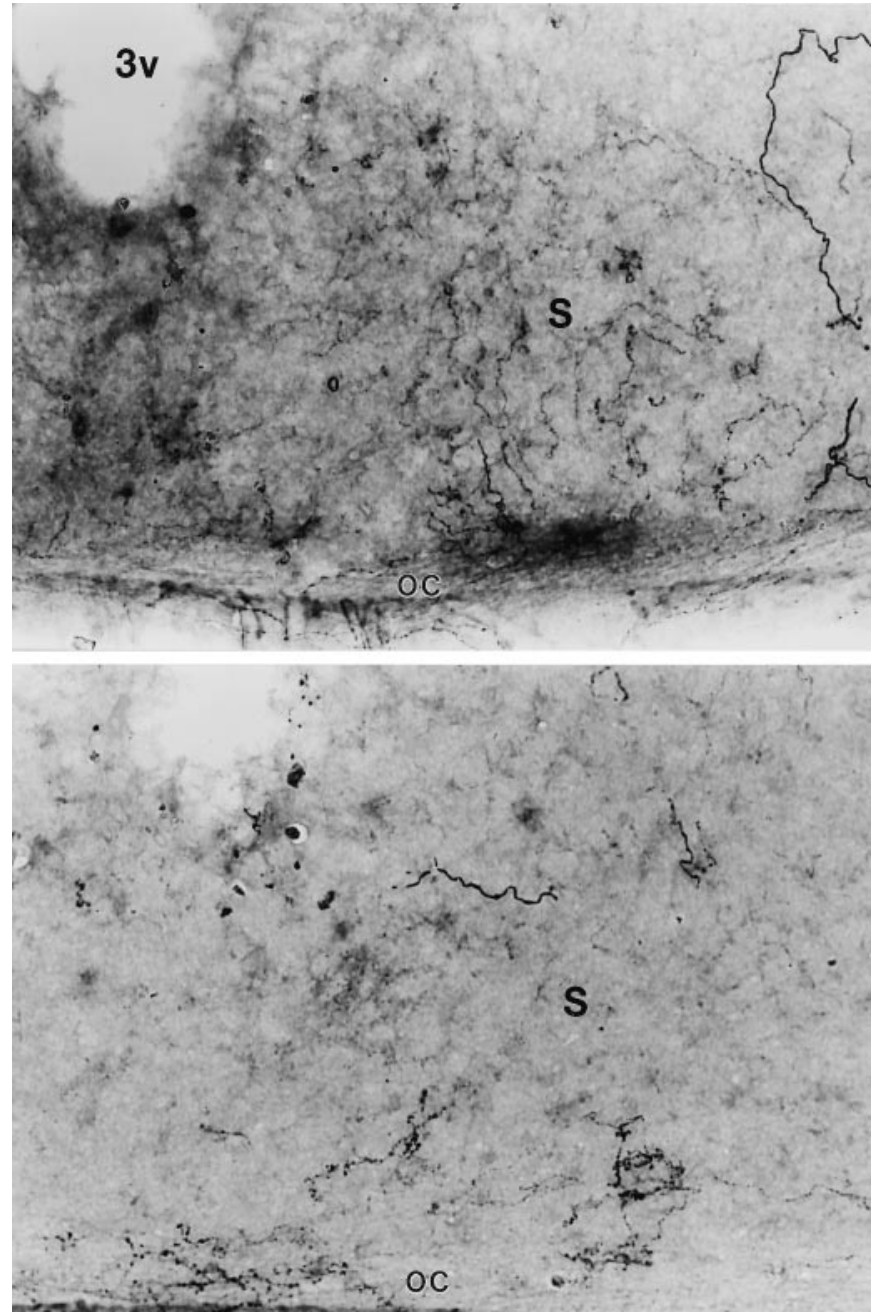

Figure 6. Photomicrographs of a single $\operatorname{SCN}(S)$ at a higher magnification in two 5,7-DHT-treated mice that exhibit only a few 5-HT immunoreactive fibers in the SCN because of sparing or regrowth. $O C$, Optic chiasm. $3 V$, Third ventricle.

ing the daily treadmill sessions by $11 \pm 0.5 \mathrm{hr}$. None of these variables differed significantly between groups 1 and 2 .

\section{Entrainment: $S C N$-ablated mice}

The role of the SCN in nonphotic entrainment has been assessed for only a few nonphotic stimuli in a few species. The SCN has been shown to be necessary for entrainment of free-running rhythms to daily melatonin injections in rats (Cassone et al., 1986) but is not necessary for entrainment to circadian schedules of food or water access in rats, hamsters, or mice (for review, see Mistlberger, 1994; Marchant and Mistlberger, 1997). One study evaluated the effects of daily schedules of activity on the organization of behavior in SCN-ablated hamsters and found evidence of synchronization of activity components in the circadian range in a few hamsters with complete lesions (Mistlberger, 1992), suggesting mediation by circadian oscillators outside of the SCN. However, similar effects were not evident in our SCN-ablated mice. Eight of nine mice with complete SCN ablations exhibited no significant circadian organization of drinking activity during the 3 weeks preceding the treadmill schedule (Fig. $7 E, F$ ). The daily treadmill running schedule had little effect on this pattern in most cases (e.g., Fig. 7E). A weak $24 \mathrm{hr}$ organization was evident 

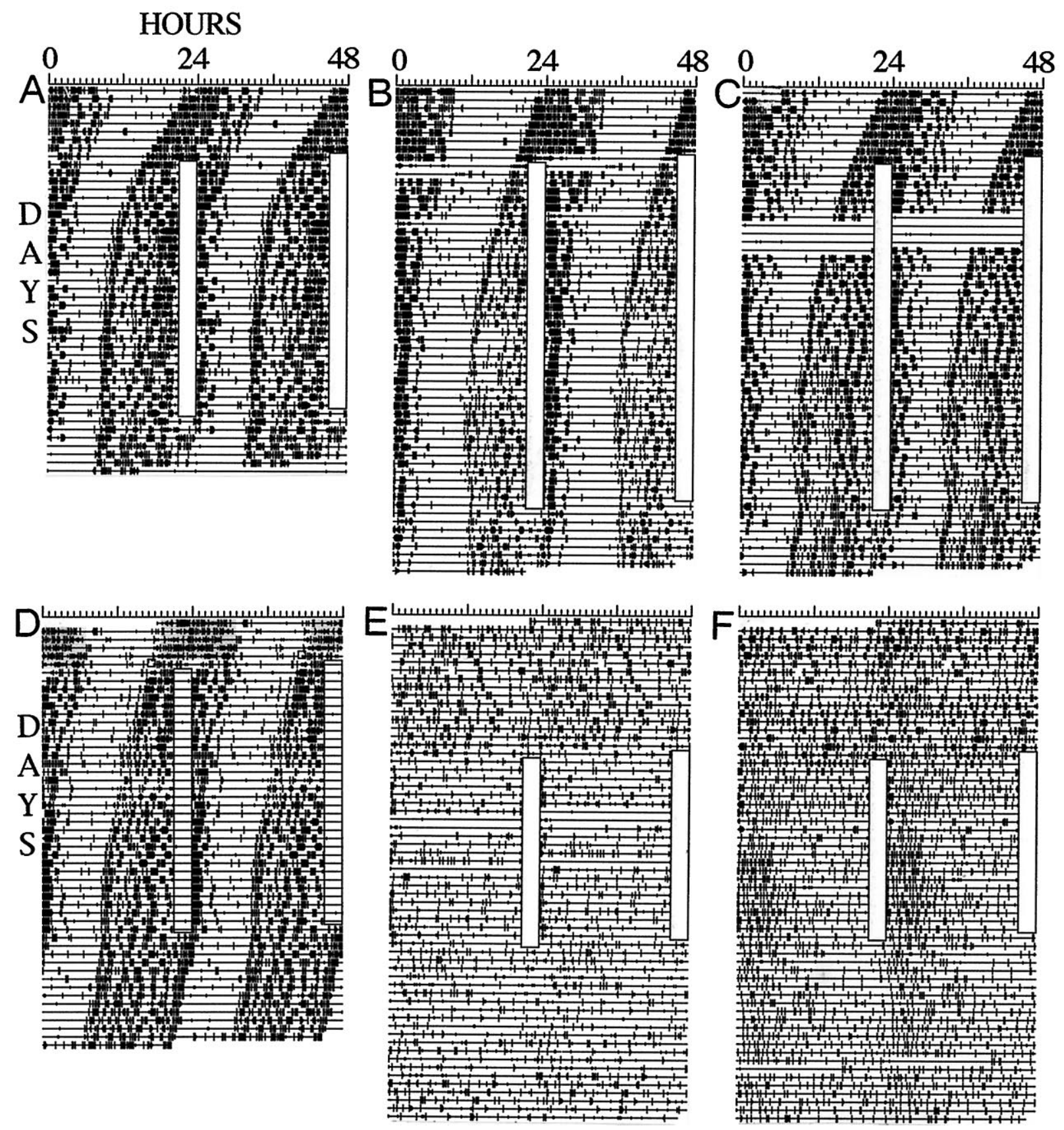

Figure 7. Drinking activity records of intact $(A-D)$ and SCN-ablated $(E, F)$ mice. Time of day is plotted left to right, and consecutive days are aligned vertically and duplicated horizontally (i.e., double-plotted). Vertical deflections indicate 10 min time bins in which drinking contacts were registered. Clear vertical bars indicate the time of day of scheduled treadmill running.

in some of the mice, caused by increased drinking after the daily treadmill sessions. However, this rhythmicity damped out within a few days when the treadmill schedule was terminated (Fig. $7 F$ ). Weak, rapidly damping rhythms likely represent a homeostatic behavioral response (drinking, eating, sleeping, or a combination) to forced running and do not provide reason to suspect that self-sustaining circadian oscillators and associated input pathways sufficient for treadmill entrainment exist outside of the SCN and its afferent network. One mouse with possible sparing of a few SCN fragments exhibited a very low amplitude free-running rhythm that did not entrain to the treadmill schedule.

Relatively few SCN neurons may be required for circadian rhythms to persist (Davis and Gorski, 1984; Harrington et al., 1993); therefore the SCN lesions were made large to ensure that all SCN neurons were removed. However, it is unlikely that a pacemaker mediating treadmill entrainment resides among nonSCN nuclei that were also damaged because, as demonstrated next, entrainment required innervation of the SCN by NPY, and the NPY source neurons in the IGL do not innervate other nuclei in the vicinity of the SCN.

\section{Entrainment: IGL-ablated mice}

Intact mice entrained when treadmill sessions overlapped with middle-to-late $\alpha$. Consequently, the treadmill schedule was timed 
to overlap with this phase in all mice with IGL lesions. In animals that did not entrain at this phase, the schedule was continued until the daily sessions completely cleared $\alpha$. In seven cases, the schedule was continued until all circadian phases were sampled without entrainment. Despite this attention to timing, only two of 15 mice that received IGL lesions entrained to the treadmill schedule (Fig. $8 A, B)$. Both of these mice sustained incomplete IGL lesions. The phase angle of entrainment in these two mice was generally similar to that in intact mice, with the daily treadmill sessions occurring late in $\alpha$ in the entrained state. One of these mice displayed an unusually short inactive period in the entrained state ( $\sim 2$ hr; Fig. $8 A$ ).

Of the remaining five mice that sustained partial IGL ablations, none entrained, but one with $\tau$ near $24 \mathrm{hr}$ seemed close to entraining, and the other four showed $\tau$ changes, in some cases reminiscent of relative coordination (Fig. $8 C$ ). Of the three IGLablated mice lacking immunocytochemical confirmation of lesion status, one showed $\tau$ modulations reminiscent of relative coordination and a $5.5 \mathrm{hr}$ phase advance when the treadmill schedule occurred late in the animal's rest phase.

Of the five mice with histologically confirmed complete IGL lesions, none entrained to the treadmill schedule (Fig. 8D-F), none showed phase shifts, and only one showed a possible slight change in $\tau$.

\section{Entrainment: 5-HT-ablated mice}

All 19 5,7-DHT-treated mice received treadmill sessions during middle-to-late $\alpha$, and six received sessions at all circadian phases. However, only two entrained to the schedule (Fig. 9A,B), and both of these exhibited strong 5-HT-IR in the SCN, indicative of incomplete lesions or nearly complete regrowth of damaged fibers. Seven mice were scored as nearly entraining. These mice either showed transient periods of entrainment not exceeding $6 \mathrm{~d}$ or had a $\tau$ very close to $24 \mathrm{hr}$ by the end of the treadmill schedule. One of these showed robust 5-HT-IR in the SCN, two showed a few IR fibers, and four showed no detectable 5-HT-IR in the SCN (Fig. 9C,F). Of the remaining 10 mice, seven showed some evidence of $\tau$ changes over the course of the treadmill schedule. Four of these had no detectable 5-HT-IR in the SCN (Fig. 9D,E). At least two of these four also showed small phase shifts when treadmill running coincided with the beginning or end of $\alpha$. Only two mice with complete 5-HT lesions failed to show some clear modulation of $\tau$ or phase during the treadmill schedule.

\section{Relation of entrainment to $\tau$}

Free-running rhythms do not entrain to zeitgebers if the difference between $\tau$ and the period of the zeitgeber (in this case, 24 hr) is too great. Consequently, it is important to establish that group differences in the percentage of animals entraining are not caused by differences in $\tau$ before the treadmill schedule. ANOVA revealed that there were no significant group differences in $\tau$ measured over the last $7 \mathrm{~d}$ before the treadmill schedule $\left(F_{(5,49)}=\right.$ $0.195 ; p>0.05)$. The group 2 intact mice were run on the treadmill beginning the day after enucleation, thus $\tau$ was measured using the first 5-7 d of the treadmill schedule. During this block of days, $\tau$ did not differ between intact mice of groups 1 and $2(p>0.05)$, nor did it differ from $\tau$ measured in group 1 mice before the treadmill schedule, indicating that this estimate of $\tau$ is valid for comparisons across groups.

\section{Relation of entrainment to home cage wheel running}

In a previous study, we found that intact mice with free access to home cage running wheels were less likely to entrain to scheduled treadmill running than were mice that did not have access to a running wheel (Marchant and Mistlberger, 1996). Nine of 15 IGL-ablated mice in this study had access to running wheels. However, only seven of these ran in their wheels. All of these mice sustained partial lesions, and two of seven entrained. Of the eight IGL-ablated mice that did not run in wheels, none entrained. By comparison, none of the intact mice in groups 1 and 2 had access to home cage wheels, yet 14 of 16 and 8 of 9 entrained, respectively. These results indicate that the low incidence of entrainment in IGL-ablated mice was not caused by home cage wheel running.

\section{Behavior: duration and amount of home cage wheel running}

Depletion of SCN 5-HT by 5,7-DHT infusions lengthens the duration of $\alpha$ in hamsters entrained to 14:10 hr LD cycles (Smale et al., 1990; Morin and Blanchard, 1991). To determine whether 5,7-DHT lesions have a similar effect in mice, wheel-running activity was averaged in 4-6 d blocks before and after 5,7-DHT infusions (excluding the first $2 \mathrm{~d}$ after surgery; $n=18$, one case lost to intermittent switch failure). Onset and end of $\alpha$ were defined as the points on the average waveform when activity counts crossed above or below, respectively, 30 counts $/ 10 \mathrm{~min}$ and stayed above or below that threshold for at least $60 \mathrm{~min}$. These criteria result in $\alpha$ durations that were consistent with those estimated by visual inspection of the average waveforms. Means were obtained for all 18 animals and for the subgroup of 14 mice that displayed little or no detectable 5-HT-IR in the SCN. Duration of $\alpha$ (i.e., the time between $\alpha$ onset and end) during the week before 5,7-DHT lesions averaged $11.34 \pm 0.27 \mathrm{hr}$, and this increased significantly to $11.94 \pm 0.25 \mathrm{hr}$ during the week after 5,7-DHT lesions (paired $t=2.55 ; p=0.02$ ). Means and differences $(t=2.15 ; p=0.05)$ were almost identical in the subgroup of 10 mice displaying no 5-HT-IR in the SCN. Expansion of $\alpha$ resulted from a significant delay of $\alpha$ end; $\alpha$ onset was unchanged. Overall, the change in $\alpha$ after 5,7-DHT inf usions was significantly related to $\alpha$ duration before surgery; mice with short $\alpha$ (i.e., 11.5 hr or less) on average showed $\alpha$ expansion $(n=8 ; 1.56 \pm 0.15 \mathrm{hr}$; Fig. 10A), whereas mice with long $\alpha(>11.5 \mathrm{hr})$ showed small changes in the range of $\pm 30 \mathrm{~min}(n=9 ;-0.03 \pm 0.05 \mathrm{hr}$; Fig. $10 \mathrm{~B})$. The net effect was movement of $\alpha$ toward $12 \mathrm{hr}$. Inspection of means revealed no apparent relation between the duration or change in $\alpha$ after 5,7-DHT lesions and the extent of 5-HT depletion.

Activity was not recorded before surgery in IGL-ablated mice, so changes in $\alpha$ could not be assessed. After IGL ablation and enucleation, the five mice with complete lesions averaged $2288 \pm$ 2271 wheel revolutions (revs)/day, which was significantly less than that of mice with partial IGL lesions (12,099 $\pm 3469 \mathrm{revs} / \mathrm{d}$; $p<0.01$ ) and that of intact mice (group 2; mean, 13,554 \pm 812 revs/d; $p<0.01)$. Mice with 5,7-DHT lesions averaged 14,832 \pm $1296 \mathrm{revs} / \mathrm{d}$ before surgery and 15,696 $\pm 1440 \mathrm{revs} / \mathrm{d}$ after surgery $(p>0.1)$, neither of which differed from that of the intact mice $(p>0.1)$.

\section{DISCUSSION}

Previous work has established that the SCN functions as a master circadian pacemaker responsible for the generation and photic entrainment of circadian rhythms (Klein et al., 1991). Recent studies further indicate that photic entrainment is likely mediated by glutamatergic retinal afferents to the SCN (Ebling, 1996) and that both 5-HT and NPY provide inhibitory modulation of this 


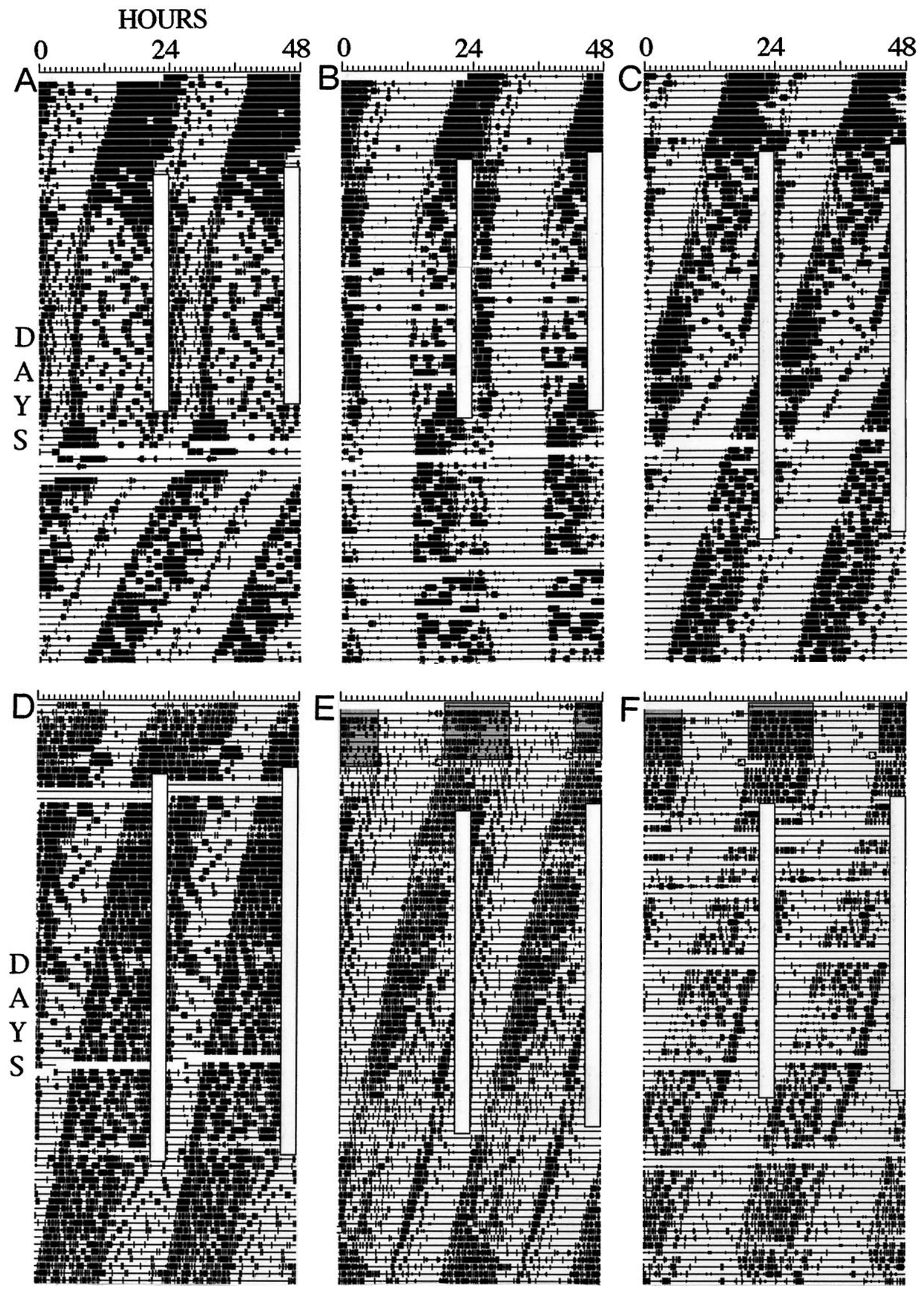

Figure 8. Wheel-running $(A-C)$ and drinking $(D-F)$ activity records of mice with partial $(A-C)$ and complete $(D-F)$ IGL ablations. Plotting conventions are described in Figure 7. 

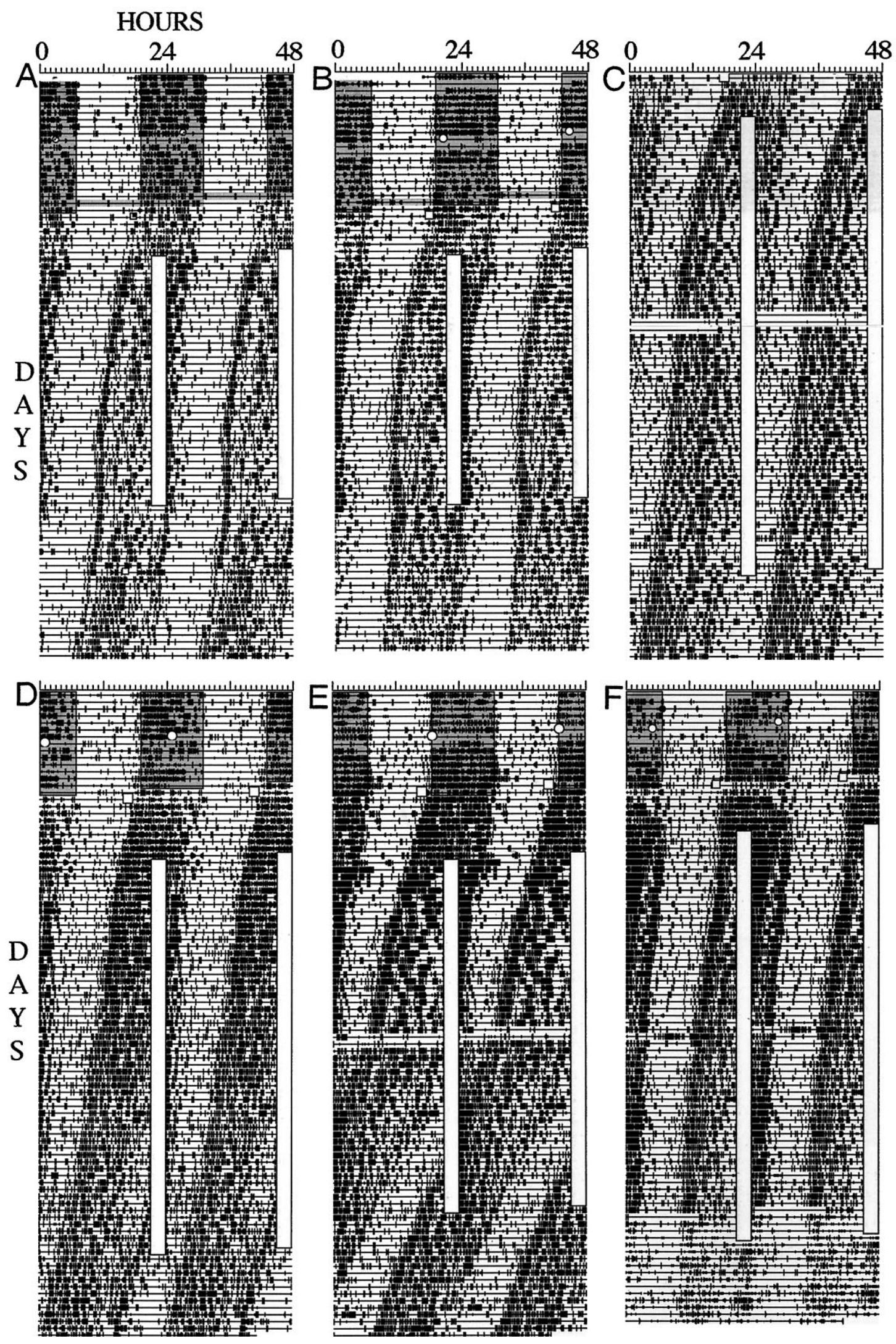

Figure 9. Drinking activity records of 5,7-DHT-lesioned mice with nearly normal levels $(A, B)$ or complete absence $(C-F)$ of 5-HT-IR in the SCN. Conventions are described in Figure 7. The time of DHT inf usions is indicated by a clear circle, and the time of enucleation is indicated by a square. The dark portion of the LD cycle before enucleation is shaded. 

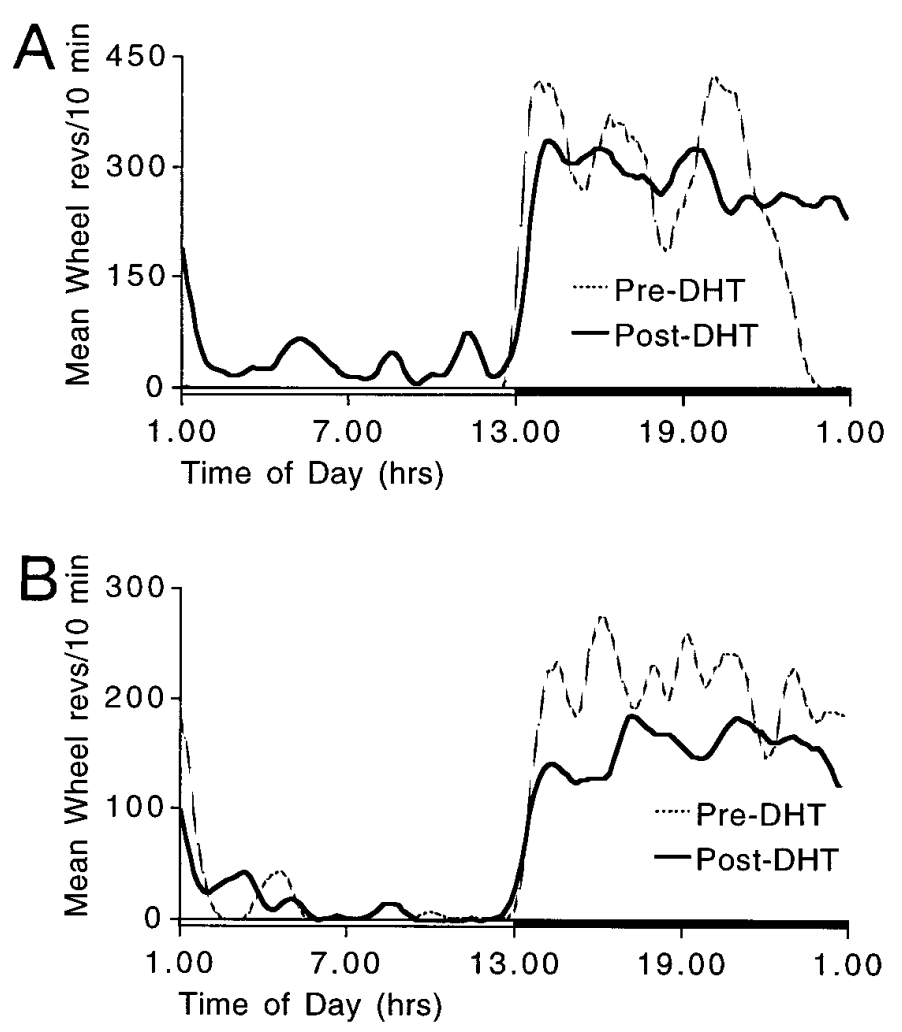

Figure 10. Average waveforms of wheel-running activity before (dashed line) and after (heavy line) 5,7-DHT inf usions in two mice that sustained complete SCN 5-HT denervations. $A$, A mouse in which the duration of the active phase expanded after 5,7-DHT infusion. $B$, A mouse in which the active phase changed very little after infusion. Data were averaged over $5 \mathrm{~d}$ and were smoothed by a weighted (1:4:1) averaging of adjacent time bins.

input (Biello, 1995; Weber et al., 1995; Miller et al., 1996; but see Shibata et al., 1994) (glutamate may in turn inhibit NPY, Biello et al., 1997). Both 5-HT and NPY activity within the SCN are increased during periods of behavioral arousal and activity (Jhanwar-Uniyal et al., 1991; Glass et al., 1992; Shinohara et al., 1993; Dudley and Glass, 1996) and may mediate inhibition of photic shifting by concurrent behavioral activity (Ralph and Mrosovsky, 1992). Behavioral activity also can phase shift and entrain circadian rhythms, independent of retinal input to the pacemaker. The results of the present study provide evidence that in mice entrainment of circadian rhythms by behavioral activity may be mediated by direct or indirect actions of both 5-HT and NPY on the SCN circadian pacemaker.

\section{Strong evidence that NPY mediates entrainment by activity}

Other studies have shown that IGL ablations in hamsters and mice can attenuate phase shifting or eliminate entrainment of circadian rhythms by nonphotic stimuli that induce activity (Johnson et al., 1988; Janik and Mrosovsky, 1994; Wickland and Turek, 1994; Edgar et al., 1997). However, complete IGL ablations also reduce activity in response to these stimuli, thus complicating the interpretation of those data. In the present study, the activity stimulus was identical for control and lesion groups, and the data clearly show that IGL ablations prevent entrainment to daily running schedules. Only 2 of 15 IGL-ablated mice entrained to the activity schedule, compared with 22 of 25 unlesioned mice, and in both of these cases, the lesions failed to eliminate NPY-IR in the SCN. Some modulations of phase or $\tau$ of free-running rhythms during the treadmill schedule were evident in some of the mice with partial IGL lesions, but no such modulations were evident in the mice completely lacking NPY in the SCN. These results constitute strong evidence that the IGL is necessary for entrainment to daily activity schedules in mice. Studies of hamsters have shown that intraventricular injections of NPY can cause phase shifts similar in timing and magnitude to those produced by scheduled bouts of wheel running (Albers and Ferris, 1984; Biello et al., 1994; Huhman and Albers, 1994) and that shifts in response to bouts of running can be blocked by injections of NPY-antibody into the SCN area (Biello et al., 1994). In addition, running activity induces Fos protein in the IGL, which colocalizes with NPY (Janik et al., 1995). Collectively, these data are consistent with a hypothesis that activation of NPY afferents is necessary for phase control of the SCN pacemaker by scheduled activity.

\section{Mixed evidence that 5-HT mediates entrainment by activity}

Another set of observations, obtained primarily from studies of rats and Syrian hamsters, has implicated 5-HT as a possible mediator of activity-induced resetting of the SCN pacemaker. Raphe nuclei unit activity and SCN 5-HT levels correlate positively with motor activity (Shioiri et al., 1991; Jacobs and Azmitia, 1992; Dudley and Glass, 1996), 5-HT agonists can produce phase shifts of behavioral rhythms or SCN rhythms in vitro that are approximately similar in timing, if not magnitude, to those induced by scheduled running (Prosser et al., 1990; Tominaga et al., 1992; Edgar et al., 1993; Bobrzynska et al., 1996a), and the 5-HT antagonists ritanserin and ketanserin can attenuate the small phase shifts caused by arousing saline injections in hamsters (Sumova et al., 1996). Reduction of hypothalamic 5-HT by 5,7DHT (Cutrera et al., 1994) or p-chloroamphetamine (Penev et al., 1995) has been reported to block the phase-shifting effects of triazolam-induced running. Finally, SCN 5-HT denervation by 5,7-DHT can prevent entrainment to scheduled yet voluntary home cage wheel activity in mice (Edgar et al., 1997). The present study provides results consistent with this latter finding and extends it to a behavioral paradigm in which activity is forced rather than voluntary, to precisely match activity levels in the lesion and control groups. Taken together, these results seem to support a hypothesis that 5-HT afferents are necessary for phase control of the SCN pacemaker by scheduled activity.

However, not all findings are consonant with this hypothesis. Although mice with complete loss of SCN 5-HT failed to entrain to $24 \mathrm{hr}$ treadmill running schedules, most did exhibit modulations of $\tau$ or phase during the schedules. Modulations imply that treadmill activity, or some correlate, affected the motion of the pacemaker but was of insufficient strength to exert stable phase control. Conceivably, if the period of the activity schedule was matched more closely to $\tau$, entrainment may have occurred.

Several other findings also cast doubt on the idea that nonphotic effects on pacemaker phase are mediated by direct 5-HT afferents to the SCN. First, phase shifts to 5-HT agonists in vivo are generally much smaller than those induced by scheduled wheel running, although they do approximate those induced by arousing saline injections (Tominaga et al., 1992; Hastings et al., 1995; Bobrzynska et al., 1996a). Second, although systemic injections of the 5-HT $1 \mathrm{a} / 7$ agonist ( \pm )-8-hydroxy-2-(di- $N$ propylamino)tetralin (8-OH-DPAT) during the middle subjective 


\begin{tabular}{lccc}
\hline \multicolumn{1}{l}{ Table 1. Effects of treadmill running on circadian rhythms in mice grouped by lesion catagory } \\
Group & Period $(\mathrm{hr})^{a}$ & Entrained (\%) & Period or phase change \\
\hline Intact 1 & $23.53 \pm 0.05$ & $14 / 16$ & $2 / 16$ \\
Intact 2 & $23.55 \pm 0.06$ & $8 / 9$ & $1 / 9$ \\
SCNx & & $0 / 9$ & $0 / 1^{b}$ \\
IGLx partial & $23.52 \pm 0.06$ & $2 / 7$ & $5 / 7$ \\
IGLx complete & $23.72 \pm 0.08$ & $0 / 5$ & $0 / 5$ \\
5-HTx partial & $23.70 \pm 0.07$ & $2 / 3$ & $1 / 3$ \\
5-HTx complete & $23.61 \pm 0.06$ & $0 / 14$ & $12 / 14$ \\
\hline
\end{tabular}

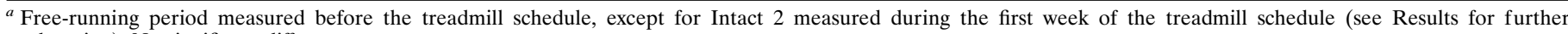
explanation). No significant differences across groups.

${ }^{b}$ All but one SCN-ablated mouse were arrhythmic before the treadmill schedule.

${ }^{c}$ Includes 10 mice with no 5-HT-IR in the SCN and 4 mice with a few scattered 5-HT fibers.

day induce phase advances, intra-SCN infusions of 8-OH-DPAT do not, suggesting that the drug produces phase shifts by actions elsewhere in the brain (Mintz et al., 1996). Third, there are two reports that depletion of SCN 5-HT in Syrian hamsters by 5,7DHT does not prevent phase shifts to activity-inducing stimuli (Meyer and Morin, 1995; Bobrzynska et al., 1996b). In addition, 5-HT lesions that did attenuate nonphotic resetting in hamsters also attenuated (Cutrera et al., 1994) or may have attenuated (Penev et al., 1995) the primary activity bout that served as the resetting stimulus. Finally, 5-HT antagonists with affinity for $5-\mathrm{HT}_{7}$ receptors, the most likely to mediate 5-HT-induced phase resetting of the SCN pacemaker (Lovenberg et al., 1993), do not attenuate activity-induced shifts in hamsters (Antle et al., 1997). Technical factors (e.g., lesion size, drug dose, or complexity of drug actions at presynaptic and postsynaptic sites) may account for some of these discrepant findings. Alternatively, 5-HT transmission may mediate nonphotic resetting to some stimuli (e.g., saline injections, which do not induce running activity) but not others (e.g., running in response to triazolam or novel wheel confinement) or may play a more important or wider role in some species (e.g., mice) than in others (e.g., hamsters). In any case, the data do not yet permit a generalization that 5-HT mediates phase control of the mammalian circadian system by behaviorally arousing stimuli.

\section{Physiological bases for interactions between 5-HT and NPY}

Our results indicate that both NPY and 5-HT may contribute to treadmill entrainment in mice. NPY and 5-HT afferents are organized both in series and in parallel with respect to the SCN. Raphe 5-HT fibers project to the IGL (Meyer-Bernstein and Morin, 1996), thus it is possible that 5-HT contributes to nonphotic resetting by modulation of IGL output to the SCN. The observation that the 5-HT agonist 8-OH-DPAT induces phase shifts after systemic but not intra-SCN application is consistent with this idea (Mintz et al., 1996). Conceivably, 5,7-DHT infusions may prevent treadmill entrainment by destroying 5-HT afferents to the IGL. We used relatively large doses of 5,7-DHT in this study to ensure a complete SCN 5-HT denervation over the several months of behavioral testing, but in no case was 5-HT-IR absent from the IGL. However, mice killed within 1 week of DHT treatment (E. G. Marchant, unpublished observations) exhibited widespread loss of 5-HT throughout the brain, including the IGL, suggesting that 5-HT-IR evident in the IGL of our mice killed up to 4.5 months after surgery may represent reinnervation, which may not be functional (Morin, 1992). Thus, the data do not rule out the possibility that nonphotic entrainment in mice involves serotonergic modulation of NPYcontaining cells in the IGL, either directly (excitation) or via interneurons (disinhibition). If so, then the main function of 5-HT receptors in the SCN may be modulation of light input, leaving in question the significance of 5-HT-induced phase shifts of SCN rhythms in vitro.

An alternative model is that NPY and 5-HT inputs converge postsynaptically within the SCN. Some NPY and 5-HT terminals make synapses on the same SCN neurons in rats (Bosler and Beaudet, 1985; Guy et al., 1987). In addition, both NPY and 5-HT affect membrane potential in SCN neurons by activation of a hyperpolarizing $\mathrm{K}^{+}$current (Prosser et al., 1994; Hall and Harrington, 1996) (J. D. Miller, personal communication). Conceivably, nonphotic resetting of SCN pacemaker cells requires changes in membrane potential and mobilization of second messenger cascades, by coactivity of NPY and 5-HT afferents. However, this model is complicated by observations that at some receptors NPY inhibits adenylate cyclase (Grundemar et al., 1993) and that adenylate cyclase inhibition can block phase shifts to 5-HT agonists in vitro (Prosser et al., 1994). Preliminary evidence suggests that NPY can antagonize phase shifts to 5-HT in the rat SCN in vitro (Prosser, 1997).

A role for presynaptic interactions is also possible, because close appositions have also been observed between NPY and 5-HT axon terminals in rat SCN (Guy et al., 1987; Ugrumov et al., 1994). However, our lesion data would imply that the interaction is facilitatory, whereas the available evidence points to inhibitory effects of NPY and 5-HT at presynaptic sites in the SCN (e.g., Obrietan and van den Pol, 1996; Pickard et al., 1996).

These models are not mutually exclusive, and there is insufficient evidence to reject categorically any. In addition, a complete model may have to accommodate critical roles for GABA transmission and nitric oxide synthesis given the findings that NPY and GABA colocalize in some SCN terminals (Francois-Bellan et al., 1990), that in vivo phase shifts to NPY (Huhman et al., 1995) and to 5-HT (Mintz et al., 1996) can be blocked by the GABA $_{\mathrm{A}}$ antagonist bicuculline, and that inhibition of nitric oxide blocks phase advances to nonphotic and photic stimuli (Ding et al., 1994; Starkey, 1996). Although direct electrophysiological evidence is lacking, the behavioral results presented here provide a basis for predicting that functionally important interactions do occur between the 5-HT and NPY components of the rodent circadian system. 


\section{REFERENCES}

Albers HE, Ferris CF (1984) Neuropeptide Y: role in the light-dark cycle entrainment of hamster rhythms. Neurosci Lett 50:163-168.

Antle MC, Marchant EG, Chubaty P, McHattie LJ, Niel L, Mistlberger RE (1997) Serotonin antagonists and agonists fail to modulate activity-induced phase shifts of circadian rhythms in Syrian hamsters. Soc Neurosci Abstr, in press.

Azmitia EC, Segal M (1978) An autoradiographic analysis of the differential ascending projections of the dorsal and median raphe nuclei in the rat. J Comp Neurol 179:641-668.

Biello SM (1995) Enhanced photic phase shifting after treatment with antiserum to neuropeptide Y. Brain Res 673:25-29.

Biello SM, Janik D, Mrosovsky N (1994) Neuropeptide Y and behaviorally induced phase shifts. Neuroscience 62:273-279.

Biello SM, Golombek DA, Harrington ME (1997) Neuropeptide Y and glutamate block each other's phase shifts in the suprachiasmatic nucleus in vitro. Neuroscience 77:1049-1058.

Bobrzynska KJ, Godfrey MH, Mrosovsky N (1996a) Serotonergic stimulation and nonphotic phase-shifting in hamsters. Physiol Behav 59:221-230.

Bobrzynska KJ, Vrang N, Mrosovsky N (1996b) Persistence of nonphotic phase shifts in hamsters after serotonin depletion in the suprachiasmatic nucleus. Brain Res 741:205-214.

Bosler O, Beaudet A (1985) VIP neurons as prime synaptic targets for serotonin afferents in rat suprachiasmatic nucleus: a combined radioautographic and immunocytochemical study. J Neurocytol 14:749-763.

Cassone VM, Chesworth MJ, Armstrong SM (1986) Entrainment of rat circadian rhythms by daily injection of melatonin depends upon the hypothalamic suprachiasmatic nucleus. Physiol Behav 36:1111-1121.

Cutrera RA, Kalsbeek A, Pevet P (1994) Specific destruction of the serotonergic afferents to the suprachiasmatic nuclei prevents triazolaminduced phase advances of hamster activity rhythms. Behav Brain Res 62:21-28.

Davis FC, Gorski RA (1984) Unilateral lesions of the hamster suprachiasmatic nuclei: evidence for redundant control of circadian rhythms. J Comp Physiol [A] 154:221-232.

Ding JM, Chen D, Weber ET, Fairman LE, Rea MA, Gillette MU (1994) Resetting the biological clock: mediation of nocturnal circadian shifts by glutamate and NO. Science 266:1713-1717.

Dudley T, Glass JD (1996) Endogenous 5-HT release in the Syrian hamster SCN. Soc Res Biol Rhythms Abstr 5:51.

Ebihara S, Mano N, Kurono N, Komuro G, Yoshimura T (1996) Vitamin B12 affects non-photic entrainment of circadian locomotor activity rhythms in mice. Brain Res 727:31-39.

Ebling FJP (1996) The role of glutamate in the photic regulation of the suprachiasmatic nucleus. Prog Neurobiol 50:109-132.

Edgar DM, Dement WC (1992) Regularly scheduled voluntary exercise synchronizes the mouse circadian clock. Am J Physiol 261:R928-R933.

Edgar DM, Miller JD, Prosser RA, Dean RR, Dement WC (1993) Serotonin and the mammalian circadian system. II. Phase-shifting rat behavioral rhythms with serotonergic agonists. J Biol Rhythms 8:17-31.

Edgar DM, Dean MR, Dement WC (1997) Serotonergic afferents mediate activity-dependent entrainment of the mouse circadian clock. Am J Physiol, in press.

Francois-Bellan AM, Kachidian P, Dusticier G, Tonon MC, Vaudry H, Bosler O (1990) GABA neurons in the rat suprachiasmatic nucleus: involvement in chemospecific synaptic circuitry and evidence for GADpeptide colocalization. J Neurocytol 19:937-947.

Glass JD, Randolph WW, Ferreira SA, Rea MA, Hauser UE, Blank JL, De Vries MJ (1992) Diurnal variation in 5-hydroxyindole-acetic acid output in the suprachiasmatic region of the siberian hamster assessed by in vivo microdialysis: evidence for nocturnal activation of serotonin release. Neuroendocrinology 56:582-590.

Grundemar L, Sheikh SP, Wahlestedt C (1993) Characterization of receptor types for neuropeptide $\mathrm{Y}$ and related peptides. In: The biology of neuropeptide $\mathrm{Y}$ and related peptides (Colmers WF, Wahlestedt C, eds), pp 197-239. Totowa, NJ: Humana.

Guy J, Bosler O, Dusticier G, Pelletier G, Calas A (1987) Morphological correlates of serotonin-neuropeptide $\mathrm{Y}$ interactions in the rat suprachiasmatic nucleus: combined radioautographic and immunocytochemical data. Cell Tissue Res 250:657-662.

Hall AC, Harrington ME (1996) Neuropeptide Y activates large conductance channels in suprachiasmatic nuclei (SCN) neurons. Soc Neurosci Abstr 22:2055.

Harrington ME, Nance DM, Rusak B (1985) Neuropeptide Y immuno- reactivity in the hamster geniculo-suprachiasmatic tract. Brain Res Bull 15:465-472.

Harrington ME, Rahmani T, Lee CA (1993) The effects of damage to suprachiasmatic nucleus neurons and efferent pathways on circadian activity rhythms in hamsters. Brain Res Bull 30:655-669.

Hastings MH, Ebling FJP, Grosse J, Herbert J, Maywood ES (1995) Immediate early genes and the neural bases of photic and non-photic entrainment. In: Circadian clocks and their adjustment, Ciba Foundation Symposium 183 (Chadwick J, Ackrill K, eds), pp 175-197. Chichester, UK: Wiley.

Huhman KL, Albers HE (1994) Neuropeptide Y microinjected into the suprachiasmatic region phase shifts circadian rhythms in constant darkness. Peptides 15:1475-1478.

Huhman KL, Babagbemi TO, Albers HE (1995) Bicuculline blocks neuropeptide $\mathrm{Y}$ induced phase advances when microinjected in the suprachiasmatic nucleus of Syrian hamsters. Brain Res 675:333-336.

Jacobs BL, Azmitia EC (1992) Structure and function of the brain serotonin system. Pharmacol Rev 72:165-229.

Janik D, Mrosovsky N (1994) Intergeniculate leaflet lesions and behaviorally-induced shifts of circadian rhythms. Brain Res 651:174-182.

Janik D, Mikkelsen JD, Mrosovsky N (1995) Cellular colocalization of Fos and neuropeptide $\mathrm{Y}$ in the intergeniculate leaflet after nonphotic phase-shifting events. Brain Res 698:137-145.

Jhanwar-Uniyal M, Beck B, Buret C, Leibowitz SF (1991) Diurnal rhythm of neuropeptide Y-like immunoreactivity in the suprachiasmatic, arcuate and paraventricular nuclei and other hypothalamic sites. Brain Res 536:331-334.

Johnson RF, Smale L, Moore LP, Morin LP (1988) Lateral geniculate lesions block circadian phase-shift responses to a benzodiazepine. Proc Natl Acad Sci USA 85:5301-5304.

Klein DC, Moore RY, Reppert SM (1991) Suprachiasmatic nucleus: the mind's clock. New York: Oxford UP.

Laemle LK, Fugaro C, Bentley T (1993) The geniculohypothalamic pathway in a congenitally anophthalmic mouse. Brain Res 618:352-357.

Lovenberg TW, Baron BM, de Lecea L, Miller JD, Prosser RA, Rea MA, Foye PE, Racke M, Slone AL, Siegel BW, Danielson PE, Sutcliffe JG, Erlander MG (1993) A novel adenyl cyclase-activating serotonin receptor (5-HT7) implicated in the regulation of mammalian circadian rhythms. Neuron 11:449-458.

Marchant EG, Mistlberger RE (1995) Morphine phase shifts circadian rhythms in mice: role of behavioral activation. NeuroReport 7:209-212.

Marchant EG, Mistlberger RE (1996) Entrainment and phase shifting of circadian rhythms in mice by forced treadmill running. Physiol Behav 60:657-663.

Marchant EG, Mistlberger RE (1997) Anticipation and entrainment to feeding time in intact and SCN-ablated C57Bl/6j mice. Brain Res, in press.

Meyer EL, Morin LP (1995) The effects of serotonin depletion on triazolam and novel wheel induced phase shifts. Soc Neurosci Abstr 20:179.

Meyer-Bernstein EL, Morin LP (1996) Differential serotonergic innervation of the suprachiasmatic nucleus and the intergeniculate leaflet and its role in circadian rhythm modulation. J Neurosci 16:2097-2111.

Miller JD, Morin LP, Schwartz WJ, Moore RY (1996) New insights into the mammalian circadian clock. Sleep 19:641-667.

Mintz EM, Huhman KL, Gillespie CF, Albers HE (1996) Microinjections of bicuculline into the SCN block the phase shifting effects of systemic injections of 8-OH-DPAT at CT7. Soc Res Biol Rhythms Abstr 5:52.

Mistlberger RE (1992) Non-photic entrainment of circadian activity rhythms in suprachiasmatic nuclei ablated hamsters. Behav Neurosci 102:192-202.

Mistlberger RE (1994) Circadian food-anticipatory activity: formal models and physiological mechanisms. Neurosci Biobehav Rev 18:171-195.

Mistlberger RE, Marchant EG, Sinclair SV (1996) Nonphotic phase shifting and the motivation to run: cold exposure reexamined. J Biol Rhythms 11:208-215.

Mistlberger RE, Sinclair SV, Marchant EG, Neil L (1997) Circadian phase shifts to food deprivation and refeeding in the Syrian hamster are mediated by running activity. Physiol Behav 61:273-278.

Morin LP (1992) Serotonergic reinnervation of the hamster suprachiasmatic nucleus and intergeniculate leaflet without functional circadian rhythm recovery. Brain Res 599:98-104.

Morin LP, Blanchard J (1991) Depletion of brain serotonin by 5,7-DHT 
modifies hamster circadian rhythm response to light. Brain Res 566:173-185.

Morin LP, Blanchard J, Moore RY (1992) Intergeniculate leaflet and suprachiasmatic nucleus organization and connections in the golden hamster. Vis Neurosci 8:219-230.

Mrosovsky N (1988) Phase response curves for social entrainment. J Comp Physiol [A] 162:35-46.

Mrosovsky N, Salmon PA (1990) Triazolam and phase-shifting acceleration re-evaluated. Chronobiol Int 7:35-41.

Obrietan K, van den Pol AN (1996) NPY depresses GABA-mediated calcium transients in developing SCN neurons: a novel form of calcium long term depression. J Neurosci 16:3521-3533.

Penev PD, Turek FW, Zee PC (1995) A serotonin neurotoxin attenuates the phase-shifting effects of triazolam on the circadian clock in hamsters. Brain Res 669:207-216.

Pickard GE, Weber ET, Scott PA, Riberdy AF, Rea MA (1996) 5HT1b receptor agonists inhibit light-induced phase shifts of behavioral circadian rhythms and expression of the immediate-early gene c-fos in the suprachiasmatic nucleus. J Neurosci 16:8208-8220.

Prosser RA (1997) NPY blocks daytime serotonergic phase advances in vitro. Soc Neurosci Abstr, in press.

Prosser RA, Miller JD, Heller HC (1990) A serotonin agonist phaseshifts the circadian clock in the suprachiasmatic nuclei in vitro. Brain Res 534:336-339.

Prosser RA, Heller HC, Miller JD (1994) Serotonergic phase advances of the mammalian circadian clock involve protein kinase $\mathrm{A}$ and $\mathrm{K}^{+}$ channel opening. Brain Res 644:67-73.

Ralph MR, Mrosovsky N (1992) Behavioral inhibition of circadian responses to light. J Biol Rhythms 7:353-359.

Shibata S, Watanabe A, Hamada T, Ono M, Watanabe S (1994) NMethyl-D-aspartate induces phase shifts in circadian rhythm of neuronal activity of rat SCN in vitro. Am J Physiol 267:R360-R364.

Shinohara K, Tominaga K, Isobe Y, Inouye SIT (1993) Photic regulation of peptides located in the ventrolateral subdivision of the suprachiasmatic nucleus of the rat: daily variations of vasoactive intestinal polypeptide, gastrin-releasing peptide, and neuropeptide Y. J Neurosci 13:793-800.
Shioiri T, Takahashi K, Yamada N, Takahashi S (1991) Motor activity correlates negatively with free-running period, while positively with serotonin contents in $\mathrm{SCN}$ in free-running rats. Physiol Behav 49:779-786.

Smale L, Michels KM, Moore RY, Morin LP (1990) Destruction of the hamster serotonergic system by 5,7-DHT: effects on circadian rhythm phase, entrainment and response to triazolam. Brain Res 515:9-19.

Starkey SJ (1996) Melatonin and 5-hydroxytryptamine phase-advance the rat circadian clock by activation of nitric oxide synthesis. Neurosci Lett 211:199-202.

Sumova A, Maywood ES, Selvage D, Ebling FJ, Hastings MH (1996) Serotonergic antagonists impair arousal-induced phase shifts of the circadian system of the syrian hamster. Brain Res 709:88-96.

Tominaga K, Shibata S, Ueki S, Watanabe S (1992) Effects of 5-HT1A receptor agonists on the circadian rhythm of wheel-running activity in hamsters. Eur J Pharmacol 214:79-84.

Turek FW, Losee-Olsen SH (1986) A benzodiazepine used in the treatment of insomnia phase-shifts the mammalian circadian clock. Nature 321:167-168.

Ugrumov MV, Popov AP, Vladimirov SV, Kasmambetova S, Novodijilova AP, Tramu G (1994) Development of the suprachiasmatic nucleus in rats during ontogenesis: serotonin-immunopositive fibers. Brain Res 673:325-330.

Van Reeth O, Turek FW (1989) Stimulated activity mediates phase shifts in the hamster circadian clock induced by dark pulses or benzodiazepines. Nature 339:49-51.

Watson RE, Weigand SJ, Clough RW, Hoffman GE (1986) Use of cryoprotectant to maintain long-term peptide immunoreactivity and tissue morphology. Peptides 7:155-159.

Weber ET, Cagle M, Rea MA (1995) Local neuropeptide Y blocks light-induced phase advances of the circadian wheel-running activity rhythm in the syrian hamster. Soc Neurosci Abstr 21:454.

Wickland CR, Turek FW (1994) Lesions of the intergeniculate leaflet block activity-induced phase shifts in the circadian rhythm of activity in the golden hamster. Brain Res 660:283-300. 